\title{
A Brief Report on the Explosion on 13 June 2021 at a Market in Shiyan, China
}

\author{
Zhe-Han Wang ${ }^{1,2}$, Pierre Guy Atangana Njock ${ }^{1,2, *}$ and Lin-Shuang Zhao ${ }^{1,2}$ \\ 1 Department of Civil and Environmental Engineering, College of Engineering, Shantou University, \\ Shantou 515063, China; 20yjwang1@stu.edu.cn (Z.-H.W.); 1shzhao@stu.edu.cn (L.-S.Z.) \\ 2 MOE Key Laboratory of Intelligent Manufacturing Technology, College of Engineering, Shantou University, \\ Shantou 515063, China \\ * Correspondence: njock@stu.edu.cn
}

Citation: Wang, Z.-H.; Atangana Njock, P.G.; Zhao, L.-S. A Brief Report on the Explosion on 13 June 2021 at a Market in Shiyan, China. Safety 2021,

7,81. https://doi.org/

10.3390/safety7040081

Academic Editor: Raphael Grzebieta

Received: 8 September 2021

Accepted: 22 November 2021

Published: 24 November 2021

Publisher's Note: MDPI stays neutral with regard to jurisdictional claims in published maps and institutional affiliations.

Copyright: (c) 2021 by the authors. Licensee MDPI, Basel, Switzerland. This article is an open access article distributed under the terms and conditions of the Creative Commons Attribution (CC BY) license (https:// creativecommons.org/licenses/by/ $4.0 /)$.

\begin{abstract}
A huge gas explosion occurred on 13 June 2021 in Shiyan City, China, resulting in 25 casualties and serious injuries to 37 people. The main victims of this explosion were stall keepers and customers buying breakfast and fresh vegetables in the food market. There is a continuous need to enhance the understanding of such unfortunate events, given the dangers they pose. This study analyzes the causes of this accident considering the general background and scenes of the explosion, and then describes the rescue operations undertaken. The investigation results revealed that the explosion was caused by the poor maintenance of gas facilities and negligence of safety regulations. It is, therefore, recommended that the control of these two main aspects be strengthened to reduce the recurrence of such unfortunate accidents.
\end{abstract}

Keywords: gas explosion; incident investigation; urban and rural reconstruction; Shiyan

\section{Introduction}

With the development of China's economy, the rate of urban construction has increased considerably in recent years [1]. The rapid development of underground transit systems [2], infrastructures [3] and buildings [4] is observed in many cities. However, some areas in these cities have experienced a rather slow urban transformation owing to various reasons, including the historical value of the existing buildings, lack of capital, and regional development plans. This state of play brings about clearly evident challenges and risks associated with the construction and maintenance of certain facilities [5]. Particularly, the maintenance of existing equipment and facilities, such as gas installations, is extremely worrying owing to the explosion risks involved [6]. Gas explosions usually occur unexpectedly and cause casualties as well as severe damage to the surrounding areas.

For instance, on 24 November 2013, a gas pipeline explosion occurred at a crossroads in Wenzhou, resulting in three injuries and material damage (four cars burned and nearby lamps destroyed) [7]. This accident originated from damage to the pipeline caused by a working excavator. It was recommended to carry out a comprehensive inventory of buried facilities prior to construction works and strengthen the protective measures around construction sites [8]. On 11 June 2016, an explosion in a canteen of an office building of a gas company in Suzhou led to the collapse of approximately $400 \mathrm{~m}^{2}$ of the threestory building, causing 11 deaths [9]. In this case, a cook forgot to cut off the gas before leaving the kitchen, resulting in the leakage of gas throughout the room [10]. There was another massive explosion at a chemical warehouse in the port city of Tianjin in 2015, which killed 165 people, most of whom were firefighters and police officers. The blast was ascribed to the illegal construction and unsafe storage of volatile materials. Particularly, the combination of excessive heat and loss of wetting agent of chemicals (nitrocellulose) stored in containers contributes to lit a fire, which later evolved into explosions [11,12]. There are many other related works from other countries, such as the collapse of the Plasco 
building in Tehran as reported in [13], the assessment of the Murray Building bombing in Oklahoma City [14], and the performance analysis of fire behavior for underground parking structures [15]. These examples emphasize the importance of strengthening the management of the aforementioned facilities and equipment. Although many studies have investigated this issue [16-19], there is a continuous need to enhance the understanding of such unfortunate events, given the dangers they pose. Recently, an explosion caused by a gas pipeline leak happened in Shiyan City, causing several casualties.

Shiyan City is located in central China's Hubei Province. Figure 1 shows the geographical location of the gas explosion site, which is intrinsic to the Yanhu Community of Zhangwan District. Specifically, the accident occurred in an old two-story building surrounded by residential buildings. The first floor mainly consisted of 19 shops (mostly eateries, pharmacies, and other businesses), while other activities were carried out on the second floor. Additionally, there were approximately 46 convenient stalls across the road. The market had already opened at the time of the incident, i.e., several people were present, buying and selling vegetables and having their breakfast [20].

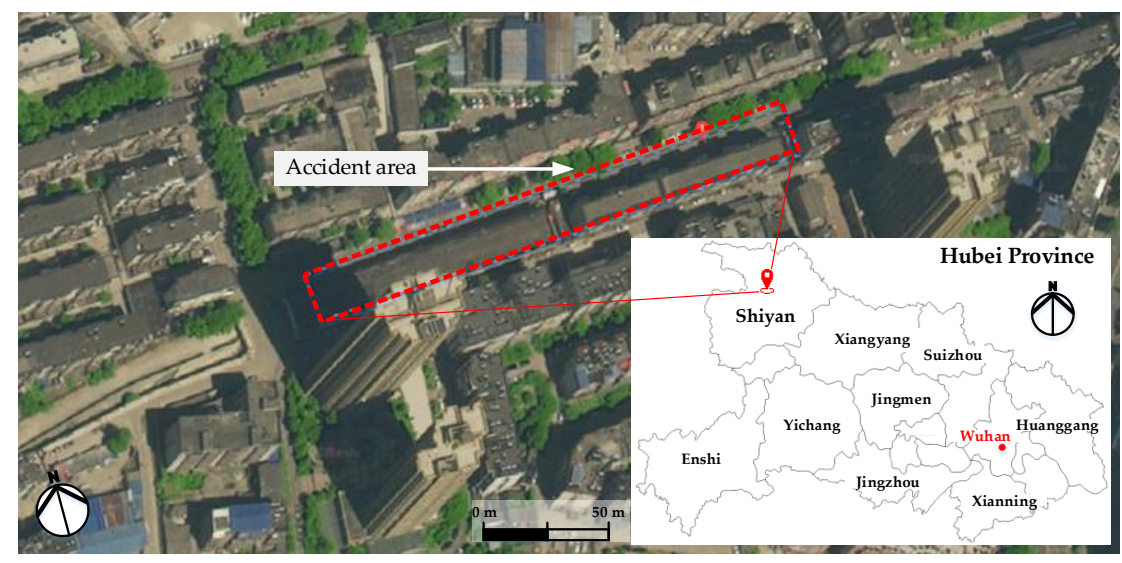

Figure 1. Location of the gas explosion site and overview of the surrounding environment.

This article reports a recent explosion accident in Shiyan City, Hubei Province. The main objective is to contribute to the knowledge in this field by providing some lessons learned from this accident. The background of this incident is first introduced. Then, the specificities of the explosion and rescue operation are presented. Finally, the potential sources of the explosion are discussed, and effective measures are suggested for mitigating similar accidents.

\section{Explosion Incident and Rescue Operations}

Explosions are very dangerous sudden events that require timely and efficient rescue operations to mitigate damage and reduce casualties. This section presents the specificities of the Shiyan market gas explosion, as well as rescue operations that were undertaken immediately after the incident.

\subsection{Explosion Incident}

\subsubsection{Buildings and Pipelines Involved in the Explosion}

Figure 2 shows the buildings and pipelines arrangement before the explosion. It can be seen that the market building was surrounded by relatively high residential buildings. This two-story steel-concrete structure was illegally constructed on a river bed in 1991 [21]. Thenceforth, the lower ground floor of the building and the river below formed a closed space from North to South and partially blocked from East to West (the space was about $107 \mathrm{~m}$ long and $14 \mathrm{~m}$ wide, the height from east to west is reduced from $4.0 \mathrm{~m}$ to $2.7 \mathrm{~m}$, and the volume was about $5300 \mathrm{~m}^{3}$ ) [21]. Moreover, the west end of the building was adjacent to the Yanhu bridge, while its east end was close to $(6.2 \mathrm{~m})$ the Yanhu community building No. 26. A convenient path was built with a cement plate between this residential 
building and the one that exploded, causing another enclosed space below the ground surface (Figure 3a).
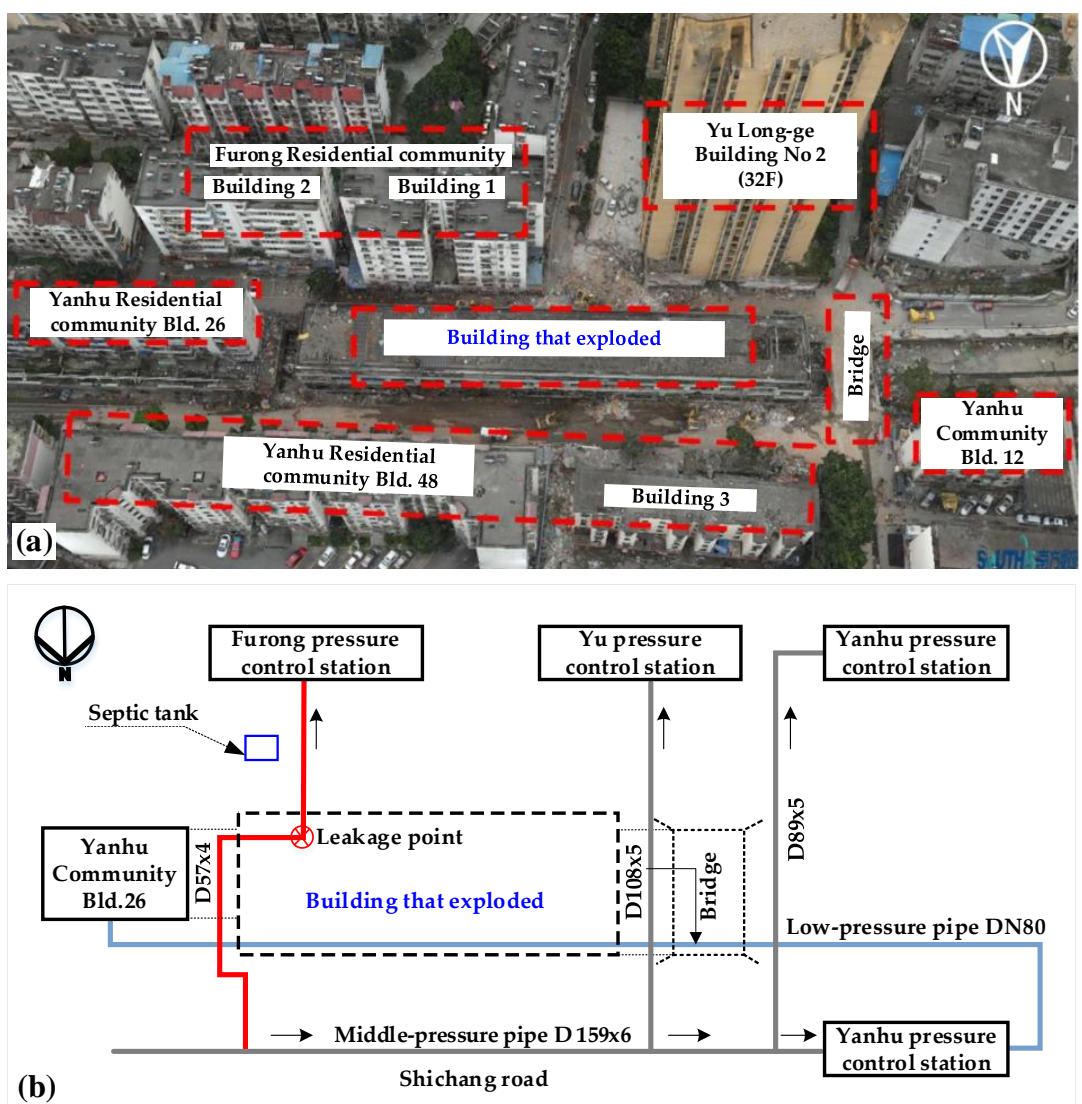

Figure 2. Main buildings and gas pipelines involved in the explosion (Recreated after [21]). (a) Surrounding buildings affected by the explosion. (b) Gas pipelines arrangement and leakage point.
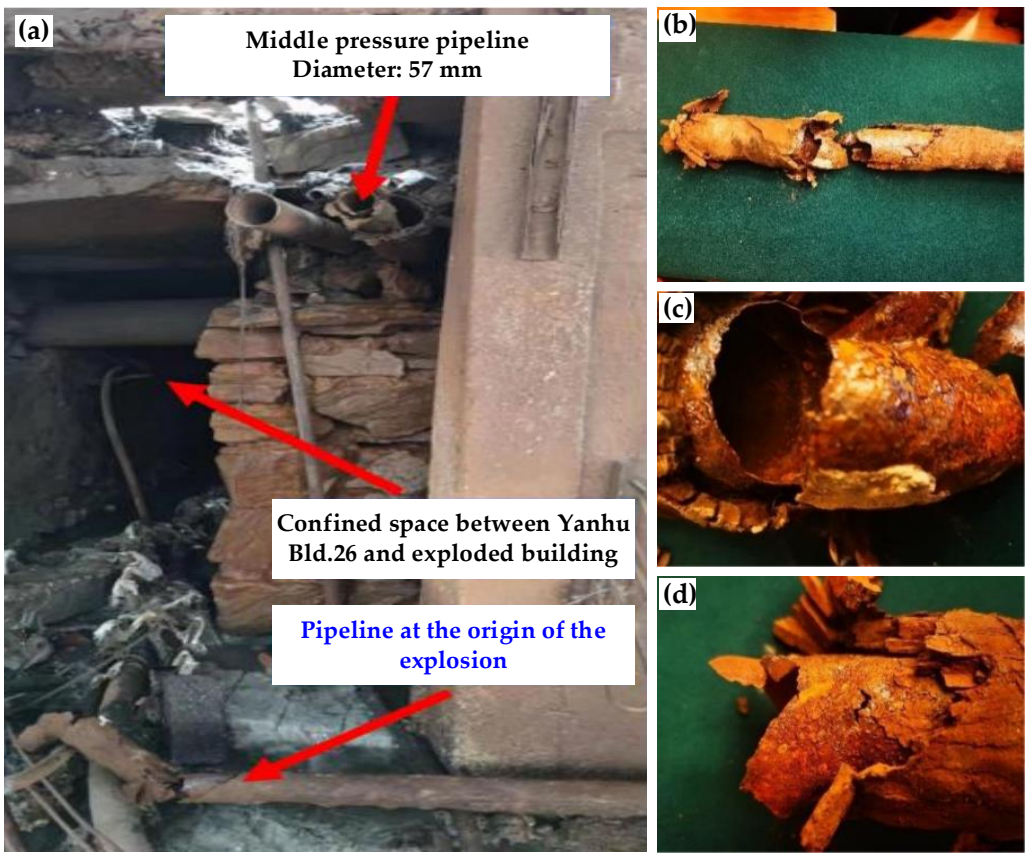

Figure 3. (a) Confined space below the ground surface and (b-d) different views of the corroded pipe (Recreated after [21]). 
Furthermore, it can be observed that the gas pipeline network in the explosion area was mainly composed of low- and medium-pressure steel pipes with various diameters. Particularly, the pipeline at the origin of the explosion (represented in red in Figure $2 b$ ) was a medium pressure pipe with a diameter of $57 \mathrm{~mm}$. It can also be seen that these pipelines were conserved in a rather inadequate environment. Under the above-mentioned conditions, the steel pipe experienced severe corrosion over time (Figure 3b), resulting in cracking and gas leakage (the leakage point was located under the building that exploded). The leaked natural gas gathered and spread to the first and second floors, which was aided by poor ventilation of the confined space below the building, given that the leaked gas quickly became concentrated. Therefore, upon reaching the explosion limit, it detonated on contacting a fire source [22].

\subsubsection{Range and Damages of the Explosion}

The blast hit shortly after 6 a.m., the time at which some residents were going to restaurants in the market for breakfast, among whom some died, while others were injured. According to some witnesses, the explosion was huge, and the resulting flying debris might have caused more injuries. In fact, according to the technical audit performed by the local government [21], the volume of natural gas accumulated in the confined space, i.e., the bottom of the accident building was approximately $600 \mathrm{~m}^{3}$. Yet, the energy of the explosion was equivalent to $225 \mathrm{~kg}$ TNT [21]. Figure 4 shows some pictures illustrating the severity of the explosion. It can be seen that the entire market building was overturned [22]. The ground floor slab on the first and second floors collapsed and fell into the river below, while the building walls and the roof were completely demolished. The explosion not only destroyed the market building but also affected the surrounding environment. Debris and fragments from the explosion were spread over a wide area, mainly due to the impact of the explosion, causing damages to the surrounding buildings. The doors and windows of the surrounding residential buildings (Furong residential community, Yanhu residential community, and Yu Long-ge building) were seriously damaged, affecting approximately 1678 residents. Further, several shops installed in front (North direction) of the market building, as well as cars parked in its vicinity were mostly destroyed. However, the environmental protection department confirmed that the accident did not cause any surrounding environmental pollution [21]. Similar explosion outcomes were reported by recent studies, and the reader can refer to them for a more comprehensive understanding [23-25].

\subsubsection{Pre-Explosion Management}

As the leaked gas accumulated in the confined space below the building, its strong smell alerted the residents, who transmitted their concern to the relevant authorities and gas company. The gas company inspected the building on 3 June; however, they found no illegal equipment or major hidden dangers. A possible reason for this oversight was that the marketplace was an overhead construction with a quasi-hidden underground section, which was basically closed (unreachable). However, according to the requirements of the code for the design of town gas (GB 50028) [26], no underground gas pipelines shall pass under buildings and large structures.

\subsection{Rescue Operation}

Figure 5 illustrates the firefighters in action, searching for and rescuing the wounded. In fact, an important task force (comprising all fire rescue personnel) was mobilized by the local government in a timely and efficient response to the blast. Specifically, the authorities established an accident rescue headquarters with eight working groups. About 913 residents and businesses at the scene of the accident were evacuated. Figure 5 shows some firefighters climbing over damaged concrete slabs to reach people trapped below. Sniffer dogs were also used in the search and rescue process, as well as for detecting other dangers. It should be noted that nearby cadres and groups also actively participated in the rescue operation, searching for survivors in the rubble [27]. The latter were taken to 
ambulances and dispatched to hospitals depending on the seriousness of their injuries. Moreover, all major hospitals in Shiyan city actively provided treatment to the injured. Because of the excessive number of injured people and insufficient storage at government blood banks, many citizens had volunteered to donate blood.

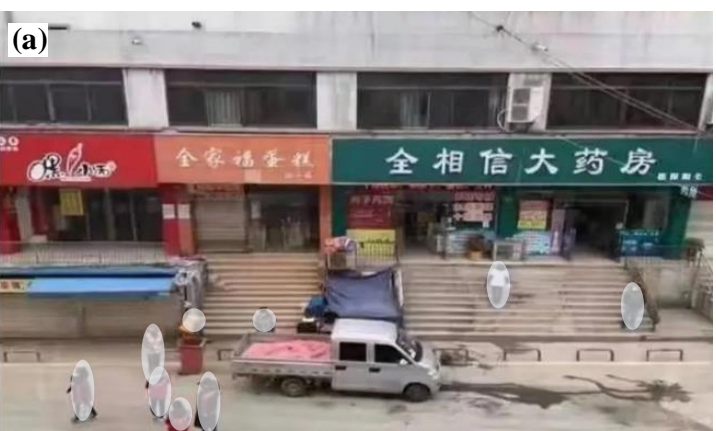

(b)

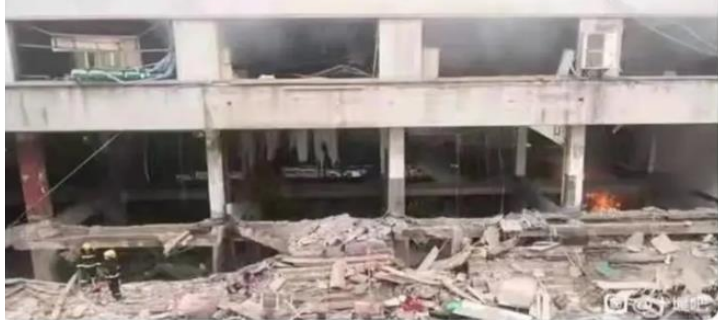

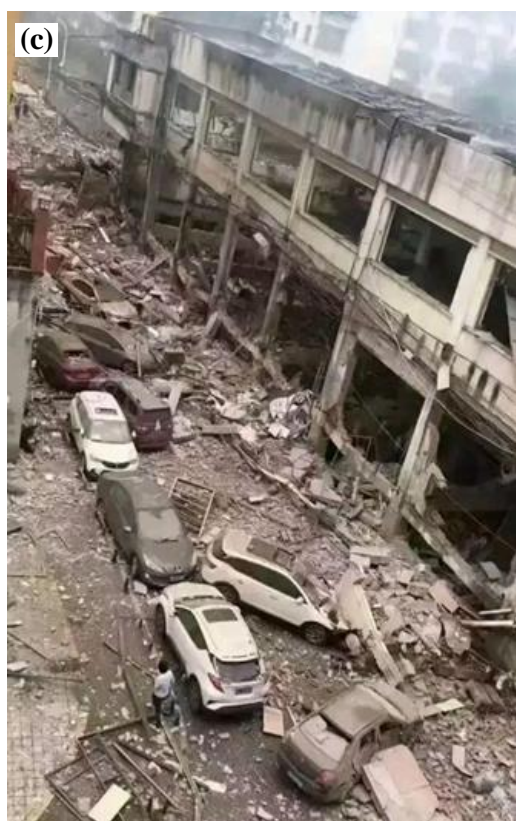

Figure 4. (a) Market building before the explosion; (b) Market building destroyed by explosion; (c) Market street impacted by the blast (source: https:/ / baijiahao.baidu.com/s?id=1702438248131929 294\&wfr=spider\&for=pc, accessed on 14 August 2021).
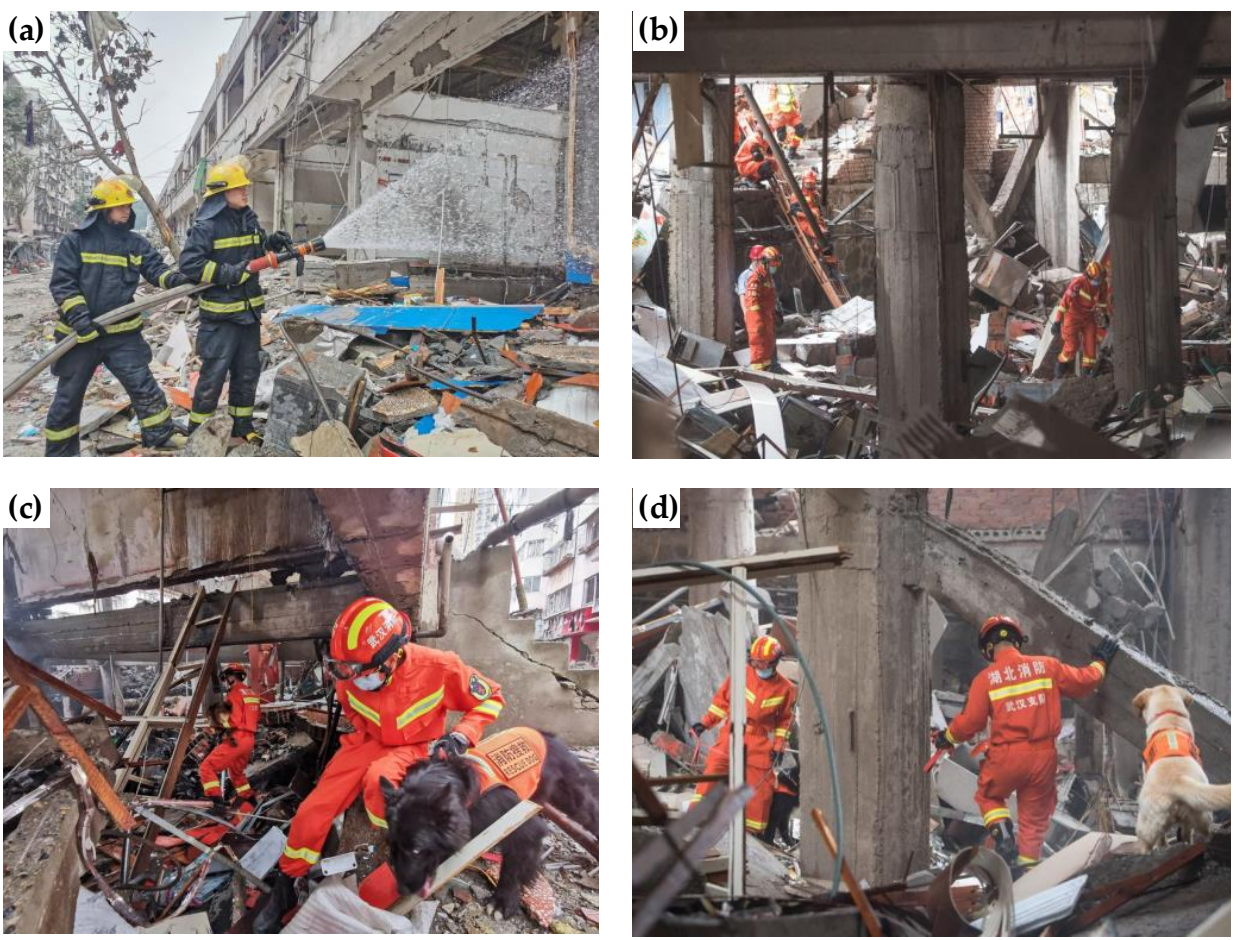

Figure 5. (a-d) Firefighters in search and rescue operation soon after the blast (Source: https: / /7news.com.au/news/disaster-and-emergency/at-least-12-dead-in-china-gas-explosion-c-3098789, accessed on 14 August 2021). 


\section{Discussion}

\subsection{Cause Analysis and Reflections}

The primary cause of the accident was found to be a gas pipeline leak. The external surface of the pipeline experienced electrochemical corrosion (Figure $3 \mathrm{~b}$ ) as a result of long exposure to a humid environment. Indeed, much research has experimentally demonstrated the influence of environmental conditions on the corrosion behavior of pipeline steel $[28,29]$. Further, the technical audit revealed that the external anti-corrosion of the pipeline elbow was not manufactured according to the anti-corrosion specifications; yet, despite a recent reform aimed at improving the condition of gas pipelines, corroded pipelines were not attended to in this specific area [21]. Therefore, this is a typical case in which an instance of inefficient management of alarm bells and/or risks has evolved into a major disaster. Before the explosion, the relevant department had already received calls from residents complaining about a strong smell of gas nearby. Subsequently, the gas company inspected the neighborhood on June 3; however, they did not find any illegal gas storage facilities or equipment. In other words, when the gas leakage occurred, no adequate measures were undertaken by the relevant entities [21], which made the residents believe that there were no risks and they could normally proceed with their daily cooking activities. Consequently, the explosion occurred as a result of the gas build-up reaching its limit in a confined space.

Moreover, the investigation results also revealed that there was a lack of information monitoring methods. At the time of the explosion, the gas company did not have online and real-time monitoring systems (in that specific area) for pressure, flow rate as those in jet grouting construction [30]. Hence, the problem can also be posed in terms of manual investigation or maintenance methods, which were very obsolete [31].

It is suggested to strengthen the safety awareness of local residents so as to enable them to take remedial measures when there are alarming signs. In the vicinity of hazardous equipment (such as pipelines for transporting flammable and explosive gases), strict requirements of the working environment should be specified. For instance, when installed underground, such equipment should be ventilated, and the warning range should be marked near the ground. Regular inspections are also needed to guarantee the integrity of the equipment and surrounding environment. For major safety inspections, it is recommended to set up a multi-layered mutual supervision model, in which the responsibilities are shared to ensure the implementation of regular inspections.

\subsection{Safety of Surrounding Buildings}

As previously discussed, many surrounding apartments were affected by the gas explosion. On the other hand, these apartment buildings (concrete structures) were relatively close to the building that exploded. It is therefore legitimate to question the effect of the explosion on the surrounding buildings, particularly with respect to the safety and construction materials used in that area. To a large extent, because of recurrent explosions in metropolitan areas, the blast community is increasing its attention on the protection of existing buildings, which are often built with the most common construction materials, such as masonry or poorly reinforced concrete [32-34]. From the blast-response standpoint, unreinforced masonry (as in the case reported herein) has a very brittle behavior under blast loads $[15,34]$, which arguably explains the considerable quantity of debris generated during the explosion, as well as a large number of victims in the surrounding. On the contrary, cast masonry can supply a high level of explosion protection due to the ductility of reinforcement. It is also primordial to keep a certain safety distance between consecutive buildings, given the high temperature and energy generated by gas explosions [32]. At the same time, design procedures must consider the nature and characteristics of building materials, as well as their capacity to resist explosion [14,35]. The current state-of-the-art research mainly focuses on the effects of duration, amplitude, and range of air-blast loads induced by explosives. Future research should be directed towards an in-depth analysis of these behaviors, especially for gas explosions. 


\subsection{Technical Framework for SAR Operations}

In addition to the administrative and technical measures to prevent gas explosion accidents, it is important to improve the efficiency of search and rescue (SAR) operations. This is particularly relevant as in many countries, including China, available SAR frameworks are primarily circumscribed to earthquake accidents, which are arguably different from gas explosion accidents. Figure 6 depicts a technical framework of SAR operations for gas explosions established based on the present case study. Typically, the proposed framework can be divided into three main stages, namely the risk reduction stage, emergency response stage, and recovery stage [36-38]. In the first stage, people trapped under rubble must be rescued, while at the same time, the residual risks of the explosion (structure collapse, fire, electrocution, intoxication, respiratory distress) should be suitably assessed and tackled. For instance, it is not recommended to use much heavy machinery at this stage to enable the rescue of victims who might still be alive under the rubble. The second stage primarily involves health care and safety control. Particularly, strengthening the on-site monitoring is critical to avoid secondary disasters. The relevant authorities should pay attention to strengthening this aspect and make sure that the professional and volunteer fighters do not become victims while on duty. As advocated by the national emergency plan of China [38], maintaining the social order (i.e., avoiding panic and chaos) is quite determinant during the second stage and when entering the third stage. Social mobilization should be systematically coordinated. Finally, it is recommended to collect all data relevant to the explosion and conduct a thorough investigation, based on which lessons and prevention measures should be drawn.

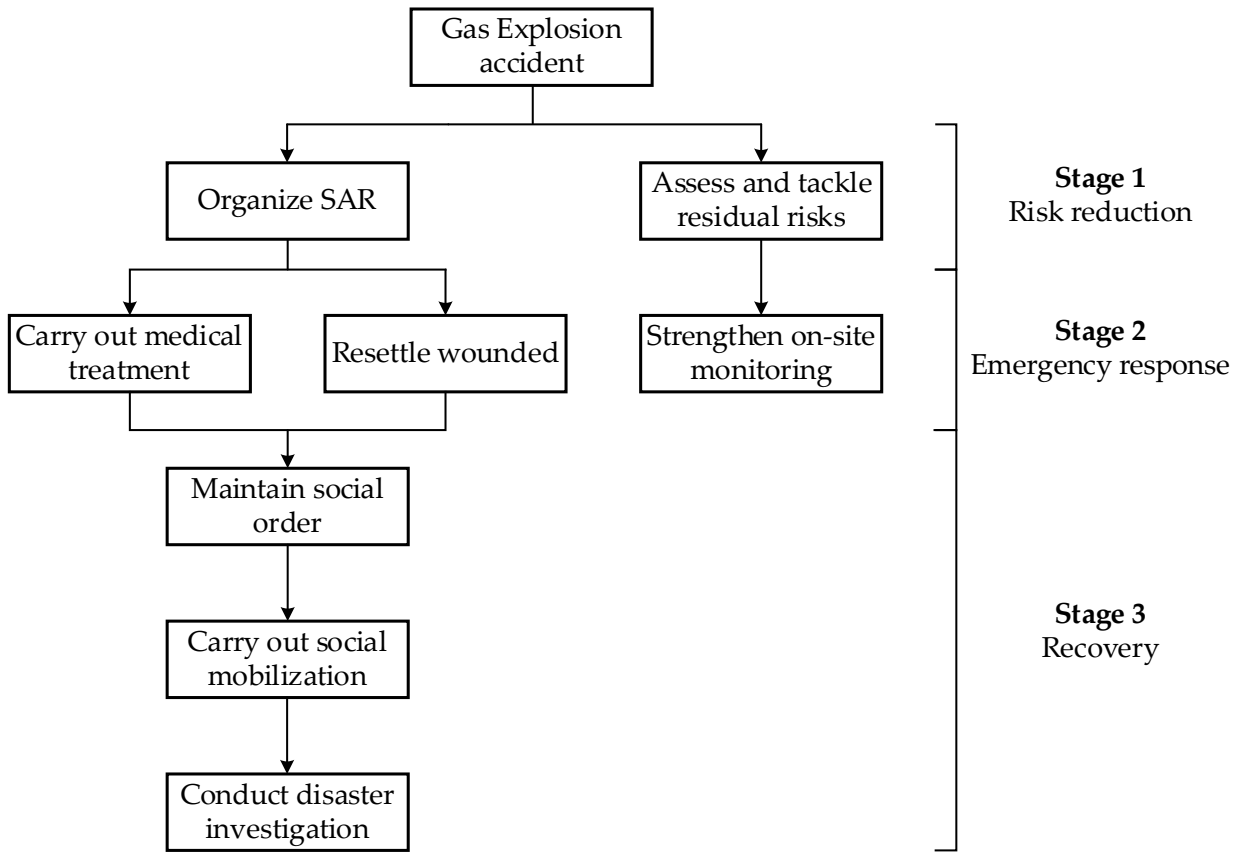

Figure 6. Technical framework for SAR operations following gas explosion.

\section{Conclusions}

This paper discusses the causes of a gas explosion that occurred on 13 June 2021 in Shiyan City. The main conclusions are as follows:

(1) The explosion occurred as a result of gas leakage from a corroded pipe installed below an unreachable part of the building. The infringement of construction regulations for pipelines and oversight of relevant services were the main causes of this incident;

(2) The rescue operation was performed rapidly and in a timely manner, thanks to efficient management of logistics. The injured were dispatched to hospitals according 
to their vital prognostics, while many citizens came forward enthusiastically to help and donate blood;

(3) In the future, it is imperative to increase the budget for the repair and daily check of engineering equipment, such as pipelines, as well as strengthen residents' safety awareness and improve escape routes in case of emergencies.

Author Contributions: Conceptualization, L.-S.Z. and P.G.A.N.; methodology, Z.-H.W.; investigation, Z.-H.W.; data curation, Z.-H.W. and P.G.A.N.; writing—original draft preparation, Z.-H.W.; writingreview and editing, P.G.A.N.; funding acquisition, L.-S.Z. All authors have read and agreed to the published version of the manuscript.

Funding: This research was funded by the National Natural Science Foundation of China (Grant No. 42102308) and the Research Funding of Shantou University for New Faculty Member (Grant No. NTF21008-2021).

Conflicts of Interest: The authors declare no conflict of interest.

\section{References}

1. Lin, S.S.; Shen, S.L.; Zhou, A.; Xu, Y.S. Approach based on TOPSIS and Monte Carlo simulation methods to evaluate lake eutrophication levels. Water Res. 2020, 187, 116437. [CrossRef] [PubMed]

2. Lyu, H.M.; Sun, W.J.; Shen, S.L.; Arulrajah, A. Flood risk assessment in metro systems of mega-cities using a GIS-based modeling approach. Sci. Total Environ. 2018, 626, 1012-1025. [CrossRef]

3. Lin, S.S.; Shen, S.L.; Zhou, A.; Xu, Y.S. Novel model for risk identification during karst excavation. Reliab. Eng. Syst. Saf. 2021, 209, 107435. [CrossRef]

4. Chin, Y.T.; Shen, S.L.; Zhou, A.N.; Chen, J. Foundation pit collapse on 8 June 2019 in Nanning, China: A brief report. Safety 2019, 9, 368. [CrossRef]

5. Li, F.; Wang, W.; Xu, J.; Dubljevic, S.; Khan, F.; Yi, J. A CAST-based causal analysis of the catastrophic underground pipeline gas explosion in Taiwan. Eng. Fail. Anal. 2020, 108, 104343. [CrossRef]

6. Lyu, H.M.; Sun, W.J.; Shen, S.L.; Zhou, A. Risk assessment using a new consulting process in fuzzy AHP. J. Constr. Eng. Manag. ASCE 2020, 146, 04019112. [CrossRef]

7. Wenzhou Gas Pipeline Explosion Injured 3 People. Available online: https://news.qq.com/a/20131124/005603.htm (accessed on 24 November 2013).

8. The Provincial Bureau Supervised and Guided the "11.24" Gas Deflagration Accident in Lucheng District, Wenzhou City. Available online: https:/ /yjt.zj.gov.cn/art/2013/11/29/art_1228977987_41139168.html (accessed on 30 October 2021).

9. Explosion in Suzhou Staff Canteen killed 11 People. Available online: http://news.cnhubei.com/xw/gn/201306/t2599740.shtml (accessed on 27 June 2021).

10. Investigation report on major LPG Explosion Accident of Office Building in Hengshan Storage Tank farm of Suzhou Gas Group. Available online: http:/ / www.jsaxw.com/news_view.php?id=8 (accessed on 30 October 2021).

11. Zhao, B. Facts and lessons related to the explosion accident in Tianjin Port, China. Nat. Hazards 2016, 84, 707-713. [CrossRef]

12. Investigation Report on Special Major Fire and Explosion Accident in Dangerous Goods Warehouse of "8.12" Ruihai Company of Tianjin Port. Available online: http://www.gov.cn/foot/2016-02/05/content_5039788.htm (accessed on 8 September 2021).

13. Behrouz, B. Fire structural response of the plasco building: A preliminary investigation report. Int. J. Civ. Eng. 2019, 17, 563-580. [CrossRef]

14. Osteraas, J.D. Murrah building bombing revisited: A qualitative assessment of blast damage and collapse patterns. J. Perform. Constr. Facil. 2006, 20, 330-335. [CrossRef]

15. Heo, I.; Kang, H.; Lee, D.H.; Oh, J.Y.; Lee, J.; Kim, K.S. Performance-based fire behaviour analysis for underground parking structures. Int. J. Urban Sci. 2016, 20, 90-100. [CrossRef]

16. Lin, C.L.; Chien, C.F. Systems thinking in a gas explosion accident-lessons learned from Taiwan. J. Loss Prev. Process Ind. 2019, 62, 103987. [CrossRef]

17. Yan, F.; Jin, C.; Li, Z.J.; Cao, R.H.; Xu, K.L. Research and development of field theory-based three-dimensional risk assessment. Part I Optim. Risk Reduct. Saf. Sci. 2019, 120, 312-322. [CrossRef]

18. Dan, S.; Kim, J.; Kim, I.H.; Cho, S.; Yoon, E.S.; Shin, D. Integrated Framework for Determining Safety Integrity Level for Improved Process Safety. J. Chem. Eng. Jpn. 2015, 48, 742-755. [CrossRef]

19. Wang, D.; Qian, X.M.; Yuan, M.Q.; Ji, T.C.; Xu, W.; Liu, S. Numerical simulation analysis of explosion process and destructive effect by gas explosion accident in buildings. J. Loss Prev. Process. Ind. 2017, 49, 215-227. [CrossRef]

20. Shiyan Gas Explosive Vegetable Farm was Built in the Early 1990s. Available online: https://news.sina.cn/gn/2021-06-13/detailikqcfnca0833446.d.html?sinawapsharesource=newsapp\&wm=3200_0024 (accessed on 13 June 2021).

21. Investigation Report on Major Gas Explosion Accident in Yanhu Community Market, Shiyan City, Hubei Province. Available online: http:/ /yjt.hubei.gov.cn/yjgl/aqsc/sgdc/202109/P020211002415958135749.pdf (accessed on 30 October 2021). 
22. At Least 12 Killed after Gas Line Explosion Rips Through Residential Compound in China's Hubei province. Available online: https:/ / www.cnn.com/2021/06/13/asia/shiyan-explosion-intl-hnk/index.html (accessed on 13 June 2021).

23. Shaluf, I.; Ahmadun, F.; Rashid, S.; Saari, M. Fire explosion at mutual major hazard installations: Review of a case History. J. Loss Prev. Process Ind. 2003, 16, 149-155. [CrossRef]

24. Ji, T.; Qian, X.; Yuan, M.; Wang, D.; He, J.; Xu, W.; You, Q. Case study of a natural gas explosion in Beijing, China. J. Loss Prev. Process Ind. 2017, 49, 401-410. [CrossRef]

25. Bariha, N.; Mishra, I.M.; Srivastava, V.C. Fire and explosion hazard analysis during surface transport of liquefied petroleum gas (LPG): A case study of LPG truck tanker accident in Kannur, Kerala, India. J. Loss Prev. Process Ind. 2016, 40, 449-460. [CrossRef]

26. Code for Design of City Gas Engineering, GB 50028-2006; National Standards of the People's Republic of China. Available online: http: / / www.codeofchina.com/standard/GB50028-2006.html (accessed on 22 November 2021).

27. Urgently Need Blood Donation! A Gas Explosion Accident Occurred in Shiyan, Hubei, and Rescue is in Progress. Available online: https: / / baijiahao.baidu.com/s?id=1702416373634524135 (accessed on 13 June 2021).

28. Zhang, G.A.; Cheng, Y.F. Electrochemical corrosion of X65 pipe steel in oil/water emulsion. Corros. Sci. 2009, 51, 901-907. [CrossRef]

29. Han, L.H.; Liu, M.; Luo, S.J.; Lu, T.J. Fatigue and corrosion fatigue behaviors of G105 and S135 high-Strength drill pipe steels in air and H2S environment. Process Saf. Environ. Prot. 2019, 124, 63-74. [CrossRef]

30. Yan, T.; Zhou, A.; Lyu, H.M. Construction efficiency during shield tunnelling in soft deposit of Tianjin. Tunn. Undergr. Space Technol. 2021, 112, 103917. [CrossRef]

31. Lei, M.; Cheng, L.; Li, M.C. Quantitative risk analysis of urban natural gas pipeline networks using geographical information systems. J. Loss Prev. Process Ind. 2013, 26, 1183-1192.

32. Zhang, K.; Zhou, A.; Balzani, D. Truncated hierarchical B-spline MPM for large deformation geotechnical problems. Comput. Geotech. 2021, 134, 104097. [CrossRef]

33. Reifarth, C.; Castedo, R.; Santos, A.P.; Chiquito, M.; López, L.M.; Pérez-Caldentey, A.; Martínez-Almajano, S.; Alañon, A. Numerical and experimental study of externally reinforced RC slabs using FRPs subjected to close-in blast loads. Int. J. Impact Eng. 2021, 156, 103939. [CrossRef]

34. Anas, S.M.; Alam, M.; Umair, M. Experimental and numerical investigations on performance of reinforced concrete slabs under explosive-induced air-blast loading: A state-of-the-art review. Structures 2021, 31, 428-461. [CrossRef]

35. Chmielewski, R.; Bak, A. Analysis of the safety of residential buildings under gas explosion loads. J. Build. Eng. 2021, $43,102815$. [CrossRef]

36. Godio, M.; Portal, N.W.; Flansbjer, M.; Magnusson, J.; Byggnevi, M. Experimental and numerical approaches to investigate the out-of-plane response of unreinforced masonry walls subjected to free far-field blasts. Eng. Struct. 2021, 239, 112328. [CrossRef]

37. Asghar, S.; Alahakoon, D.; Churilov, L. A comprehensive conceptual model for disaster management. J. Humanit. Assist. 2006, 1360, 1-15. Available online: http:/ / sites.tufts.edu/jha/files/2011/04/a193.pdf (accessed on 12 November 2021).

38. National Overall Emergency Plan. Available online: http://www.gov.cn/yjgl/2006-01/08/content_21048.htm (accessed on 30 October 2021). 